\section{Chiral Silylene-Spaced Divinylarene Copolymers}

\author{
Yen-J u Cheng, ${ }^{\mathrm{t}, \neq}$ Hui Liang, ${ }^{\mathrm{t}, \perp}$ and \\ Tien-Yau Luh*,t,t,\$
}

Department of Chemistry, National Taiwan University, Taipei, Taiwan 106; Institute of Chemistry, Academia Sinica, Taipei, Taiwan 115; and Institute of Polymer Science and Engineering, National Taiwan University, Taipei, Taiwan 106

Received May 26, 2003

Revised Manuscript Received J une 27, 2003

There has been an ever burgeoning interest in synthetic chiral polymers because of their potential applications for optoelectronic devices, ${ }^{1}$ enantioselective sensors, ${ }^{2,3}$ and catalysis. ${ }^{4}$ It is known that the chirospectroscopic property is transferred from the chiral auxiliary to the polymeric backbone as witnessed by its circular dichroitic (CD) properties. ${ }^{5-15}$ Thus, in the presence of chiral substituents, conjugated polymers may adopt helical conformation and show characteristic induced CD curves. ${ }^{6-10} \mathrm{~F}$ or random coil polymers, the CD curves appeared to be relatively weak because of the cancellation of the transition dipole moments. ${ }^{11}$ However, aggregation may play a pivotal roleto enhance the CD properties. ${ }^{12-16}$ The chemistry of silylene-spaced conjugated copolymers is well-documented.17-28 We recently discl osed a series of silylene-spaced alternating donor-acceptor copolymers which exhibit efficient intrachain energy transfer between donor and acceptor chromophores.29 These copolymers may form a random coil so that intrachain chromophore-chromophore interaction may occur. 30,31 It is envisaged that the introduction of chiral auxiliary into these copolymers would lead to the transfer of chiroptical properties through aggregation. We now wish to report the synthesis and photophysical sutdies of the first optically active silylene-spaced divinylarene copolymers $\mathbf{1}$ and $\mathbf{2}$ (see Chart 1).

In the beginning of this research, we synthesized a pair of enantiomeric copolymers 1 (1a: $70 \%$ yield, $\mathrm{M}_{\mathrm{n}}$ $=15$ 900, $\mathrm{PDI}=2.15$; 1b: $77 \%$ yield, $\mathrm{M}_{\mathrm{n}}=16300$, $\mathrm{PDI}$ $=2.27$ ) by employing rhodium-catalyzed hydrosilylation of bis(alkyne) 4 with bis(vinylsilane) $5^{29,30}$ The CD curves shown in Figure 1 suggested that $\mathbf{1 a}$ and $\mathbf{1 b}$ are mirror images. The UV-vis spectrum for $\mathbf{1}$ is also included in Figure 1 for comparison. Apparently, the chiroptical properties have been transferred from the chiral auxiliary to the aromatic chromophore in copolymers $\mathbf{1}$. The fluorescence spectra of $\mathbf{1 a}\left(\lambda_{\mathrm{ex}}=300 \mathrm{~nm}\right)$ at two different concentrations are shown in Figure 2. It is noteworthy that, at the concentration of the CD measurements, $\lambda_{\text {em }}$ shifted to longer wavelength due to aggregation. At low concentration, the CD intensity was too weak to observe.

Our next step was to synthesize a pair of enantiomeric copolymers 2 (2a: 87\% yield, $\mathrm{M}_{\mathrm{n}}=9900$, $\mathrm{PDI}=2.56$; 2b: $82 \%$ yield, $\left.M_{n}=9900, P D I=2.74\right)$ from 4 and 6 in

\footnotetext{
† Department of Chemistry, National Taiwan University.

₹ Institute of Chemistry, Academia Sinica.

$\S$ Institute of Polymer Science and Engineering, National Taiwan University.

${ }^{\perp}$ On leave from Zhongshan Universtiy, Guangzhou, 1999-2000.
}

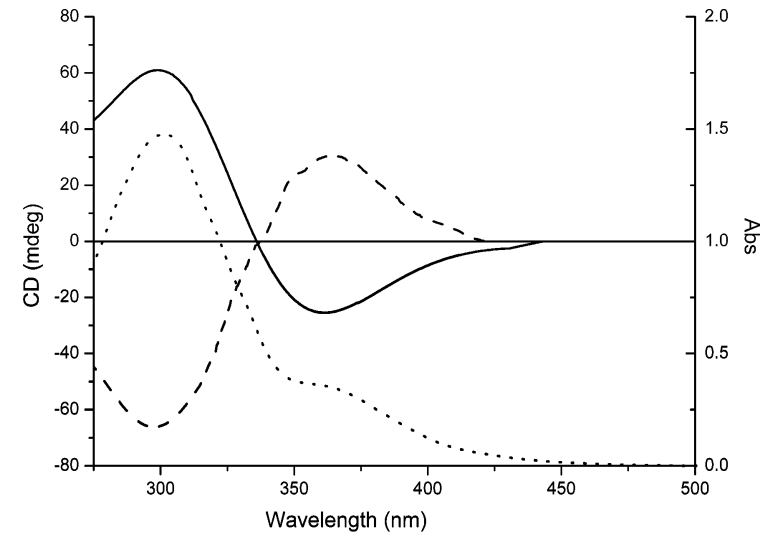

Figure 1. CD curves of $\mathbf{1 a}$ (solid line) and $\mathbf{1 b}$ (dash line) (1.5 $\mathrm{g} / \mathrm{L}$ in chloroform) and the UV - vis spectrum of la (dotted line).

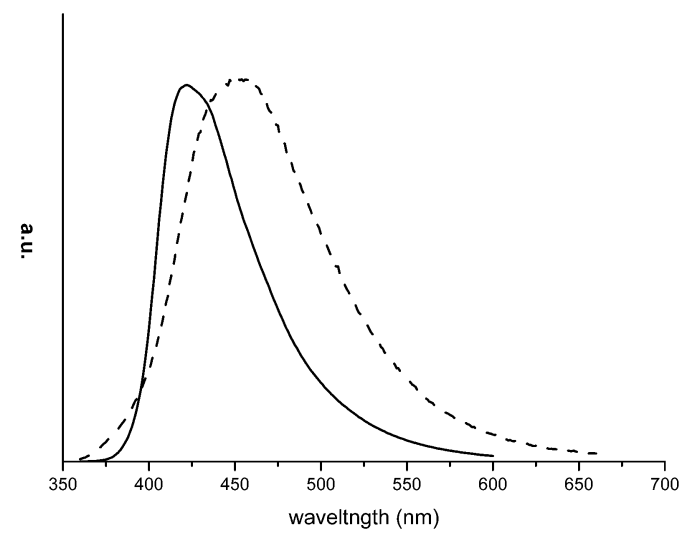

Figure 2. Normalized emission spectra of $\mathbf{1 a}$ in chloroform at different concentrations: $1.5 \mathrm{~g} / \mathrm{L}$ (dash line) and $1.5 \mathrm{mg} / \mathrm{L}$ (solid line).

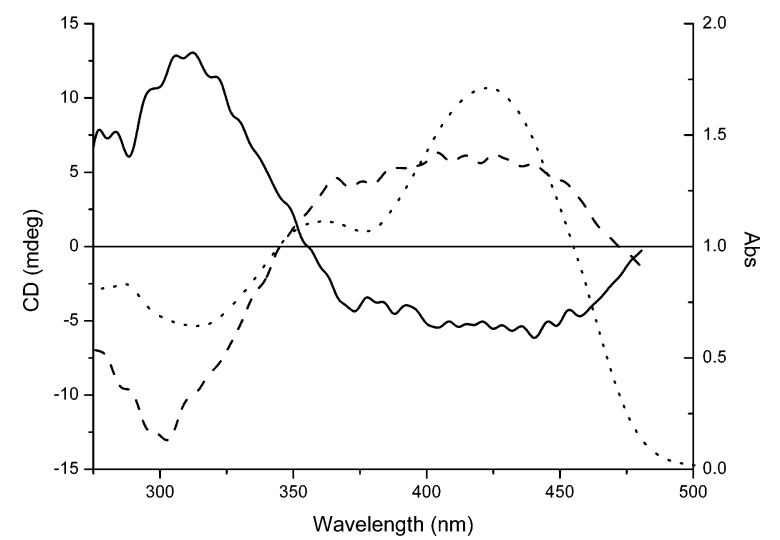

Figure 3. $C D$ curves of $\mathbf{2 a}$ (solid line) and $\mathbf{2 b}$ (dash line) (1 $\mathrm{g} / \mathrm{L}$ in chloroform) and the UV - vis spectrum of $\mathbf{2 a}$ (dotted line).

a similar manner as that described above. Again, the $C D$ curves of $\mathbf{2} \mathbf{a}$ and $\mathbf{2} \mathbf{b}$, which matched very well with the absorption spectrum of $\mathbf{2}$, are al so mirror images of each other as shown in Figure 3. In these cases, the CD curves were extended to the longer wavelength region due to the absorption of the second terphenylenetetravinylene chromophore in $\mathbf{2}$. The fluorescence profile of $\mathbf{2 a}$ showed a maximum at $448 \mathrm{~nm}$ which was ascribed to the emission of the terphenylene-tetravinylene chromophore. Apparently, energy transfer 28 from the dial koxydivinyl benzene moiety in $\mathbf{2}$ to this terphenyl ene- 


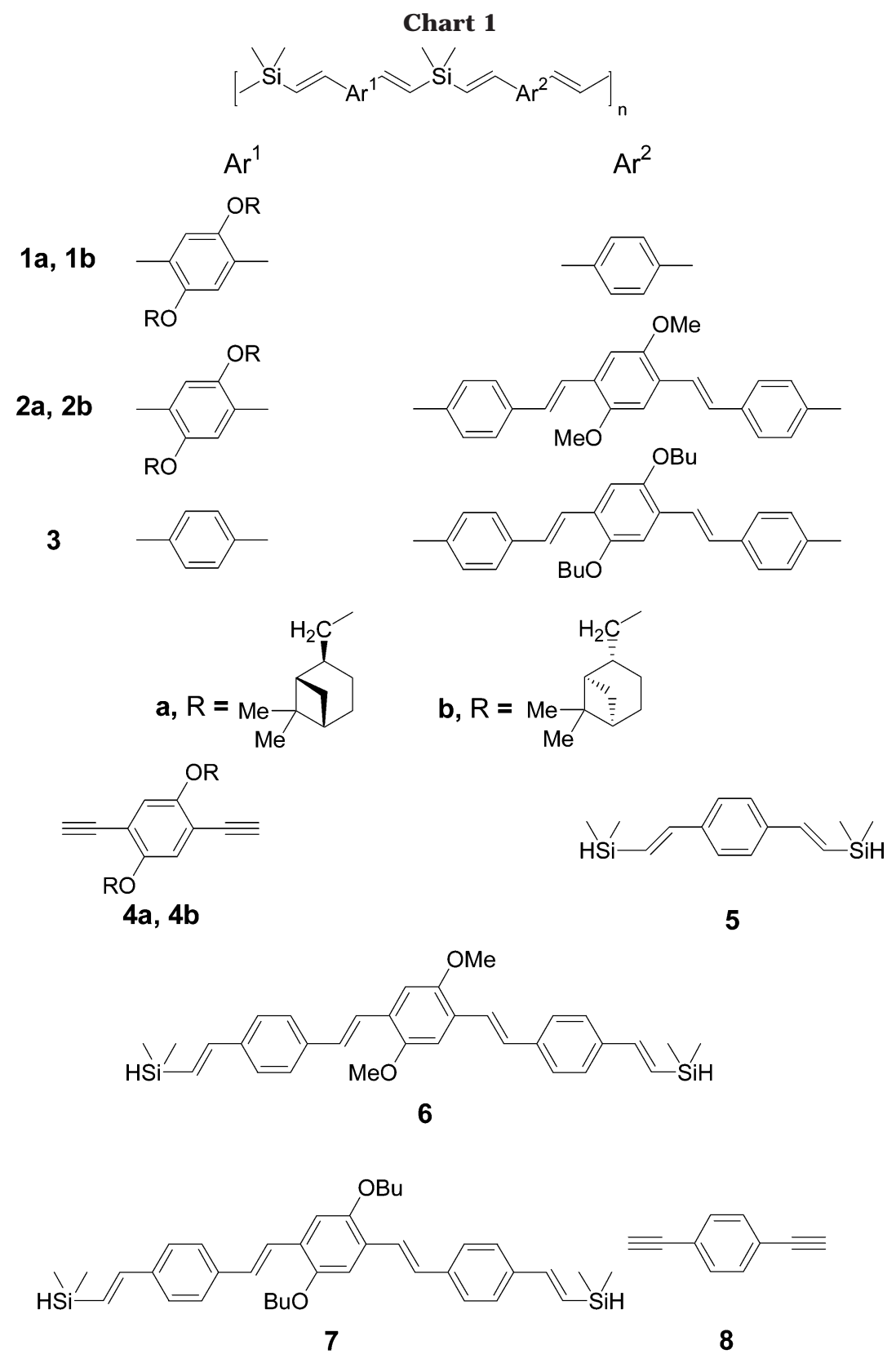

tetravinylene chromophore may occur. Again, at the concentration of the CD experiment, aggregation may occur as evidenced by the red shift of the emission maximum.

As just mentioned, aggregation may appear to be the pivotal factor to dictate the CD properties of coplymers $\mathbf{1}$ and 2. It is worthy to note that no CD curves were observed for the corresponding monomer 4 at $1.5 \mathrm{~g} / \mathrm{L}$.

In addition, we have examined the CD measurements of a mixture of copolymer $\mathbf{l a}$ and copolymer $\mathbf{3}$ (81\% yield from the hydrosilylation of 7 with $8, M_{n}=6600$, PDI = 2.32). As shown in Figure 4, the CD curve is similar but not the same as that of 1a alone. Presumably, interaction between $\mathbf{1 a}$ and $\mathbf{3}$ may occur through aggregation, which may lead to slight modification of the CD profile. Even when the concentration of the solution was increased by 10-fold, the CD profile was slightly modified within the same wavel ength range, no extension to longer wavelength being observed. It seems likely that no interchain transfer of chiroptical properties between $\mathbf{1 a}$ and $\mathbf{3}$ would occur under these conditions.
In summary, we have demonstrated the first example of chiral silylene-spaced divinylarene copolymers. Aggregation apparently plays an important role in dictat-

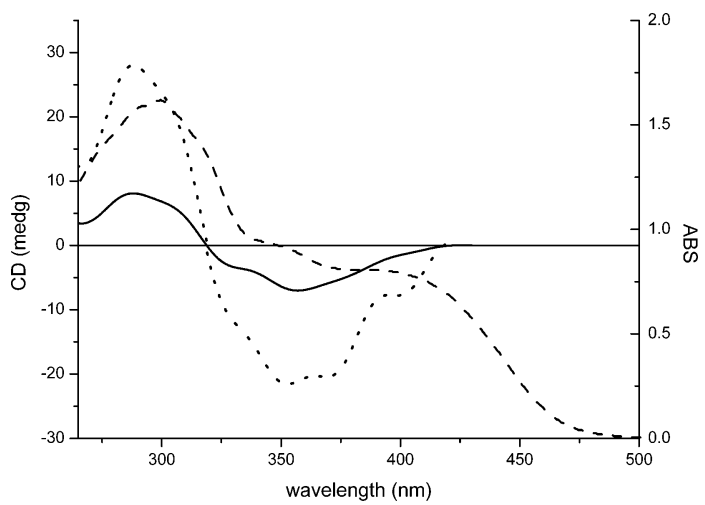

Figure 4. $C D$ curves of a mixture of $\mathbf{1 a}(1.5 \mathrm{~g} / \mathrm{L})$ and $\mathbf{3}(0.7$ $\mathrm{g} / \mathrm{L}$ ) in chloroform (solid line) and of a mixture of $\mathbf{l a}(15 \mathrm{~g} / \mathrm{L})$ and $3(7 \mathrm{~g} / \mathrm{L})$ in chloroform (dotted line) and its UV-vis spectrum (dash line). 
ing the circular dichroitic properties of these copolymers. Further extension to related systems is under investigation.

Acknowledgment. We thank the Ministry of Education and the National Science Council of the ROC for financial support.

Supporting Information Available: Synthetic scheme and experimental details for the synthesis of $\mathbf{1 - 3}$ and relevant monomeric starting materials leading to these copolymers and fluorescence spectra of $\mathbf{2} \mathbf{a}$ at different concentrations. This material is available free of charge via the Internet at http:// pubs.acs.org.

\section{References and Notes}

(1) Peeters, E.; Delmotte, A.; J anssen, A. J .; Meijer, E. W. Adv. Mater. 1997, 9, 493

(2) Yashima, E.; Maeda, K.; Okamoto, Y. Nature(London) 1999 399, 449.

(3) Yashima, E.; Matsushima, T.; Okamoto, Y. J . Am. Chem. Soc. 1997, 119, 6345.

(4) Pu, L. Acta Polym. 1997, 48, 116

(5) Petters, E.; Christiaans, M. P. T.; J anssen, R. A.J .; Schoo, H. F. M.; Dekkers, H. P. J . M.; Meijer, E. W. J . Am. Chem. Soc. 1997, 119, 9909.

(6) Nakano, T.; Okamoto, Y.; Hatada, K. J . Am. Chem. Soc. 1992, 114, 1318

(7) Ito, Y.; Miyake, T.; Hatano, S.; Shima, R.; Ohara, T.; Suginome, M. J . Am. Chem. Soc. 1998, 120, 11660

(8) Fujiki, M. J . Am. Chem. Soc. 1994, 116, 11976.

(9) Green, M. M.; Peterson, N. C.; Sato, T.; Teramoto, A.; Cook, R.; Lifson, S. Science 1995, 268, 1860

(10) Moore, J. S.; Gorman, C. B.; Grubbs, R. H. J . Am. Chem. Soc. 1991, 113, 1704.

(11) Harada, N.; Nakanishi, K. Circular Dichroic Spectroscopy; Oxford University Press: Oxford, 1983.
(12) Reidy, M. P.; Green, M. M. Macromolecules 1990, 23, 4225

(13) Bouman, M. M.; Meijer, E. W. Adv. Mater. 1995, 7, 385.

(14) Langeveld-Voss, B. M. W.; J anssen, R. A. J .; Christiaans, M. P. T.; Meskers, S. C. J .; Dekkers, H. P. J . M.; Meijer, E. W. J . Am. Chem. Soc. 1996, 118, 4908.

(15) Nakashima, H.; Fujiki, M.; Koe, J . R.; Motonaga, M.J . Am Soc. Chem. 2001, 123, 1963.

(16) Tang, H.-Z.; Fujiki, M.; Sato, T. Macromolecules 2002, 35, 6439.

(17) Hu, S. S.; Weber, W. P. Polym. Bull. (Berlin) 1989, 21, 133.

(18) Corriu, R. J . P.; Guerin, C.; Henner, B.; Kuhlmann, T.; J ean, A.; Garnier, F.; Yassar, A. Chem. Mater. 1990, 2, 351.

(19) Ohshita, J .; Kanaya, D.; I shikawa, M.; Koike, T.; Yamanaka, T. Macromolecules 1991, 24, 2106.

(20) Wu, H. J .; Interrante, L. V. Macromolecules 1992, 25, 1840.

(21) Pang, Y.; Ijadi-Maghsoodi, S.; Barton, T. J . Macromol ecules 1993, 26, 5671.

(22) Malliaras, G. G.; Herrema, J . K.; Wildeman, J .; Wieringa, R. H.; Gill, R. E.; Lampoura, S. S.; Hadziioannou, G. Adv. Mater. 1993, 5, 721.

(23) Kim, H. K.; Ryu, M.-K.; Lee, S.-M. Macromolecules 1997 30, 1236.

(24) Miao, Y.-J .; Bazan, G. C. Macromolecules 1997, 30, 7414.

(25) Mori, A.; Takahisa, E.; Kajiro, H.; Nishihara, Y.; Hiyama, T. Macromolecules 2000, 33, 1115 .

(26) Li, H.; West, R. Macromolecules 1998, 31, 2866.

(27) Oshita, J .; Takada, A.; Kunai, A.; Komaguchi, K.; Shiotani, M.; Adachi, A.; Sakamaki, K.; Okita, K.; Harima, Y.; Konugi, Y.; Yamashita, K.; I shikawa, M. Organometallics 2000, 19, 4492.

(28) Kwak, G.; Masuda, T. J . Polym. Sci., Part A: Polym. Chem. 2002, 40, 535 .

(29) Cheng, Y.-J .; Hwu, T.-Y.; Hsu, J .-H.; Luh, T.-Y. Chem Commun. 2002, 18, 1978.

(30) Chen, R.-M.; Chien, K.-M.; Wong, K.-T.; I in, B.-Y.; Luh, T.Y.; Hsu, J .-H.; Fann, W.J . Am. Chem. Soc. 1997, 119, 11321.

(31) Chen, R.-M.; Luh, T.-Y. Tetrahedron 1998, 54, 1197. MA0347058 